\title{
Subplatysmal Endoscopic Guided Endotracheal Tube Cuff Inflation Facilitates Working Space Creation in Transoral Endoscopic Thyroidectomy, A Novel Technique
}

\author{
Kadem SG*1, Mohamd SA ${ }^{2}$ and Jawad $\mathrm{MM}^{3}$ \\ ${ }^{1}$ Department of Surgery, Al-Shiffa General Hospital, Iraq \\ ${ }^{2}$ ENT Speciality surgeon, Department of Surgery, Alshiffa General Hospital, Iraq \\ ${ }^{3}$ General surgeon, Department of Surgery, Alshiffa General Hospital, Iraq
}

*Corresponding author: Sadq Ghaleb Kadem, Department of Surgery, Al-Shiffa General

\section{Case Report}

Volume 4 Issue 1

Received Date: February 22, 2020

Published Date: March 27, 2020

DOI: $10.23880 /$ ijsst-16000142

Hospital, Basrah, Iraq, Tel: +9647806432219; Email: sadiqalsaidi222@yahoo.com

\section{Abstract}

Transoral endoscopic thyroidectomy is a natural orifice thyroid surgery, minimally invasive and completely scar free. However, the working space of this procedure is relatively small and is also difficult to create compared with that of other remote-access thyroidectomy procedures. Hence, we described a new modification using endotracheal tube cuff inflation guided by an endoscope to create initial subplatysmal working space under direct vision. In this study, we first created a tract from the chin to just distal to the thyroid cartilage, after which a cuffed endotracheal tube was inserted through the middle oral vestibular incision and guided by endoscope for correct position. Sequential cuff inflations were performed to dilate the entire subplatysmal tunnel. Subplatysmal endoscopic guided endotracheal tube cuff inflation is a simple and effective method for creation of larger initial working space in transoral thyroidectomy with less blind blunt tissue dissection, that. greatly facilitating subsequent trocar insertion and further dissection.

Keywords: Transoral endoscopic thyroidectomy; Natural orifice thyroid surgery; Anuwong's TOETVA procedure; Endotracheal tube cuff pressure

Abbreviations: TOETVA: Transoral Endoscopic Thyroidectomy Vestibular Approach.

\section{Introduction}

In 1996, Gagner M, reported feasibility of endoscopic approach to the parathyroid glands [1]. After that, a number of techniques simultaneously started being called as minimally invasive thyroid surgery to minimize incisional scar of the conventional open thyroidectomy over the anterior aspect of the neck. All these techniques still leaving a scar in the endoscopic port's site entry; in the neck, axilla, breast or chest wall [2-4]. Recently, Transoral endoscopic thyroidectomy has been developed; it is a natural orifice thyroid surgery, minimally invasive and completely scar free [5-8]. The refinement of this transoral thyroidectomy technique was well-established and described by Anuwong
A., as the transoral endoscopic thyroidectomy vestibular approach (TOETVA) with excellent clinical results [9].

The initial step in the standard Anuwong's TOETVA procedure is to create subplatysmal working space extended from thyroid cartilage to the suprasternal notch; first, by hydro - dissection with normal saline, using Veress needle inserted through vestibular incision to create multiple tracts, then, by blunt tissue dissection using a Kelly clamp to dissect a tract passing through the jaw to the level of the thyroid cartilage. Then an Olive head dilator use to dilate these tracts to create multiple tunnels extended along the anterior aspect of the neck. After that and with aid of Co2 insufflation, the laparoscopic camera inserted through central vestibular $10 \mathrm{~mm}$ trocar to guide the insertion of other two $5 \mathrm{~mm}$ working ports. With use of energy sealing device, the tissues intervening between these tunnels are divided to create 


\section{International Journal of Surgery \& Surgical Techniques}

larger single working space to complete the procedure of TOETVA [9].

The frequent blind uses of the Veress needle, Kelly clamp and Olive head tissue dilator have been reported to be traumatic and may causes injuries to the skin and to the soft tissues in the region resulting in penetration of skin and/or postoperative ecchymosis and swelling. Moreover, the resulting preliminary working space is very small that makes insertion of trocars difficult and even after that, collision of the instruments frequently occurs within this small and crowded space [10]. All these difficulties may represent a challenge, especially for surgeon beginner in TOETVA procedure makes them, unwilling to try using this technique. To refine this step of TOETVA procedure; Liang TJ, et al. developed a method using balloon dilatation via a Foley catheter to create the initial working space [11]. Although, this method results in a less blunt dissection, it may result in false passages due to blind insertion of the catheter and the metallic urologic stylet that used to straighten the foley catheter may slip from the catheter tip leading to inadvertent injuries. Hence, we described a new modification using balloon dilatation via a cuffed endotracheal tube guided by an endoscope inserted through endotracheal tube itself to create initial subplatysmal working space under direct vision.

\section{Case Report}

After general anaesthesia, patient subjected to transoral endoscopic thyroidectomy were placed in a supine position with hyperextension of the neck. A transverse $15-\mathrm{mm}$ incision was made in the middle oral vestibule. Then, a Kelly clamp was applied to deepen the wound and to dissect a tract, keeping close to the mandibular periosteum until entering the subplatysmal space, then continue blunt dissection until about $2 \mathrm{~cm}$ below the mandibular syphilis and until, it can accommodate the tip of blunt tissue dilator. In this method we use cervix dilator size $(8 / 11)$ as a blunt tissue dilator passing through the vestibular incision to create a single subplatysmal tunnel with one stroke extended to the level just distal to the thyroid cartilage (Figure 1). The cervix dilator has a smooth curvature in its longitudinal axis make it more suitable than olive head dilator to pass the acute angle in the sub mental region without injury to the skin.

We use a cuffed endotracheal tube size $6.5 \mathrm{~mm}$, which needs to be shortened by cutting the proximal part of tube to fit the $20 \mathrm{~cm}$ length of a $5 \mathrm{~mm}$ endoscope (Figure 2). The $5 \mathrm{~mm}, 0$-degree endoscope was inserted into the tube (Figure 3 ) to guide its insertion through the vestibular wound and through the preliminary subplatysmal tunnel. Insufflation of $\mathrm{Co}_{2}$ to the working space was done simply through a syringe needle inserted through the side wall of the tube outside the vestibular wound. We generally perform balloon dilatation from the cranial to the caudal ends. After visual confirmation of the tube placement in the desired location in the tunnel (Figure 4), the cuff of endotracheal tube is inflated with $10-15 \mathrm{cc}$ air and kept inflated to $10-15 \mathrm{~s}$. Then, the cuff deflated and the tube is inserted deeper for another course of dilatation. It usually takes approximately 3-4times to fully dilate the entire subplatysmal tract. After that, the endotracheal tube was removed and a $10 \mathrm{~mm}$ trocar was inserted to adapt the $10 \mathrm{~mm} 30$ - degree endoscope. Next, two 5-mm trocars were inserted near the bilateral mouth angle. Additional sharp dissection with an energy device or hook cautery was performed to extend the subplatysmal space to the desired borders (Figure 5). After that the steps of TOETVA procedure were the same as previously described by Anuwong A [9].

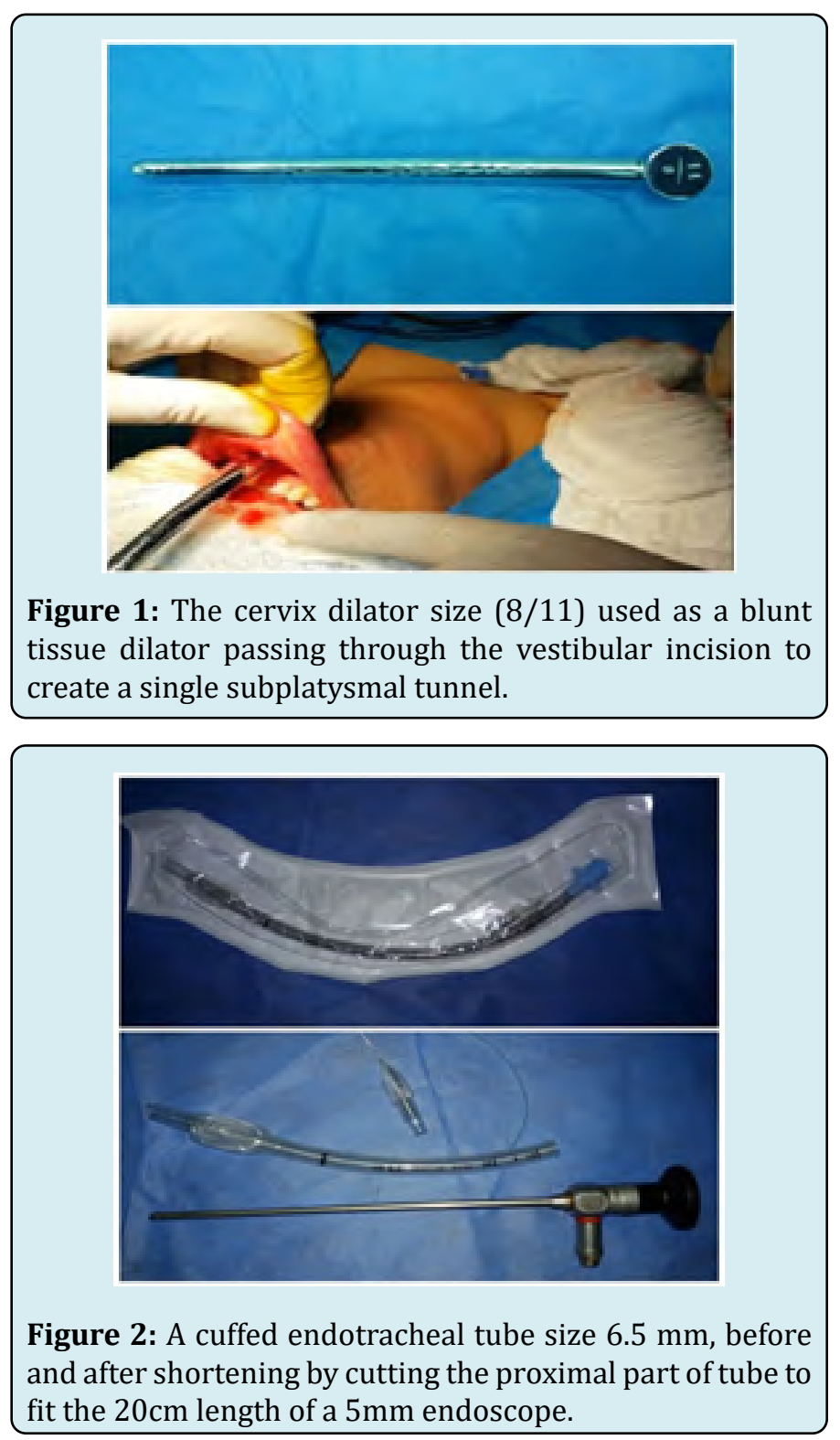



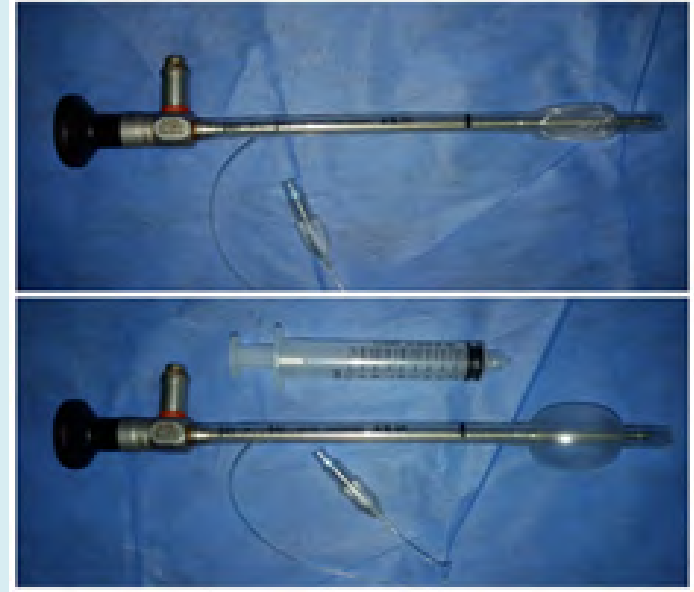

Figure 3: A 5mm, 0-degree endoscope was inserted into the tube.

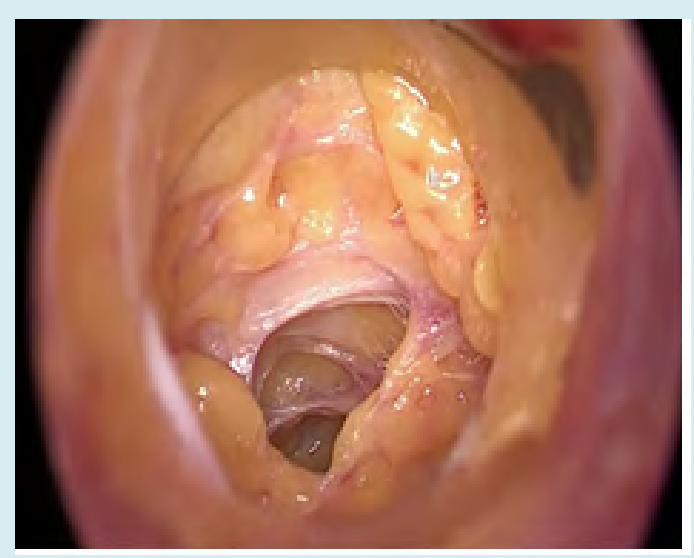

Figure 4: visual confirmation of the tube placement in the desired location in the subplatysmal tunnel.

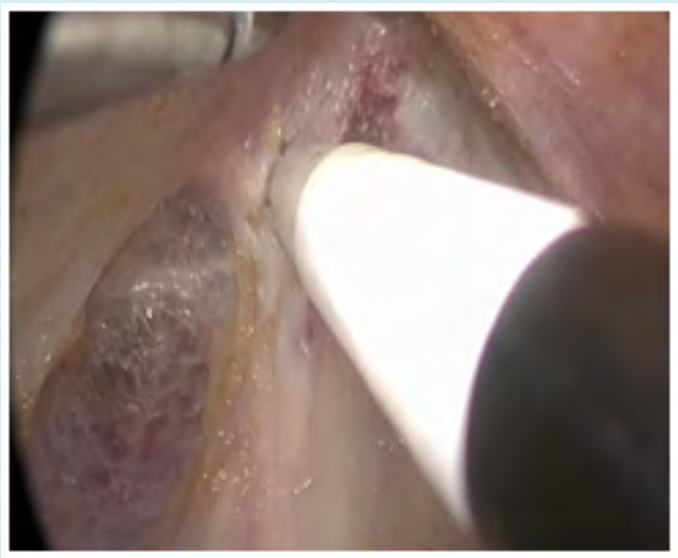

Figure 5: Additional sharp dissection with an energy device or hook cautery was performed to extend the subplatysmal space to the desired borders.

\section{Discussion}

During implementation of any new techniques, the surgeons, must realize the responsibility of recording and sharing appropriate successes and shortcomings inherent in these techniques. From our experience in TOETVA procedure, we believed that some steps of this technique need to be refine and one of these steps is the subplatysmal working space creation.

Balloon tissue dissection has been reported to be successful in facilitate dissection during laparoscopic extra peritoneal herniorrhaphy [12]. Although, the subplatysmal space in the neck is much dense than the extra peritoneal space in the groin area, the balloon dilatation with cuffed endotracheal tube or with Foley catheter can still prove very helpful because lesser working space is required in transoral thyroidectomy than in the totally extra peritoneal hernia repair. Our new modification using cuff inflation via a cuffed endotracheal tube is characterize by the following benefits: first, it needs less blind blunt tissues dissection by creating single, short distance subplatysmal tunnel using curved cervix dilator. Second, the endotracheal tube insertion to the preliminary tunnel and the tissues dissection with cuff inflation were completely guided under direct vision via endoscope inserted through the endotracheal tube itself. Third, the possibility of continues Co2 insufflation of the operative field during this technique make the space lead open, facilitating correct tube insertion. Fourth, the endotracheal tube itself is transparent provides good light trans illumination and as a result, good visualization. Fifth, unlike foleys catheter balloon, the safe pressure of the endotracheal tube cuff was predetermined by 20-30 $\mathrm{cmH}_{2} \mathrm{O}$ and the volume of air that needed to achieve this safe pressure was about $10-15$ cc $[13,14]$. This safe volume of cuff expansion was enough to create sufficient preliminary subplatysmal working space that facilitate trocars insertion and accommodates other instruments without so much collision. Finally, our idea of using endoscopic guided endotracheal tube cuff inflation for tissue dissection is a simple and could open the way for manufacturing a new device specific for creation of subplatysmal working space in transoral thyroidectomy.

\section{Conclusion}

Subplatysmal endoscopic guided endotracheal tube cuff inflation is a simple and effective method for creation of the initial working space in transoral thyroidectomy. It decreases blind blunt tissue dissection and provides larger space with better visualization, greatly facilitating subsequent trocar insertion and further dissection. 


\section{International Journal of Surgery \& Surgical Techniques}

\section{References}

1. Gagner M (1996) Endoscopicsubtotal parathyroidectomy in patients with primary hyperparathyroidism. Br J Surg 83(6): 875.

2. Ikeda Y, Takami H, Sasaki Y, Takayama J, Kurihara H (2004) Are there significant benefits of minimally invasive endoscopic thyroidectomy? World J Surg 28(11): 1075-1078.

3. Inabnet WB, Gagner M (2001) Endoscopic thyroidectomy. J Otolaryngol 30(1): 41-42.

4. Ikeda Y, Takami H, Sasaki Y, Niimi M. (2000) Endoscopic neck surgery by the axillary approach. J Am Coll Surg 191(3): 336-340.

5. Witzel K, von Rahden BH, Kaminski C, Stein HJ (2008) Transoral access for endoscopic thyroid resection. Surg Endosc 22(8): 1871-1875.

6. Wilhelm T, Metzig A (2011) Endoscopic minimally invasive thyroidectomy (eMIT): a prospective proof-ofconcept study in humans. World J Surg 35(3): 543-551.

7. Nakajo A, Arima H, Hirata M, Mizoguchi T, Kijima Y, et al. (2013) Trans-Oral Video- Assisted Neck Surgery (TOVANS). A new transoral technique of endoscopic thyroidectomy with gasless premandible approach. Surg Endosc 27(4): 1105-1110.
8. Wang C, Zhai H, Liu W, Li J, Yang J, et al. (2014) Thyroidectomy: a novel endoscopic oral vestibular approach. Surgery 155(1): 33-38.

9. Anuwong A (2016) Transoral Endoscopic Thyroidectomy Vestibular Approach: A Series of the First 60 Human Cases. World J Surg 40(3): 491-497.

10. Fernandez-Ranvier G, Meknat A, Guevara DE, Inabnet WB (2019) Transoral Endoscopic Thyroidectomy Vestibular Approach. JSLS 23(4): e2019.00036.

11. Liang TJ, Tsai CY, Chen IS (2020) Foley Balloon Facilitates Creation of Working Space in Transoral Thyroidectomy. World J Surg.

12. Misra MC, Kumar S, Bansal VK (2008) Total extra peritoneal (TEP) mesh repair of inguinal hernia in the developing world: comparison of low-cost indigenous balloon dissection versus direct telescopic dissection: a prospective randomized controlled study. Surg Endosc 22(9): 1947-1958.

13. Gilliland L, Perrie H, Scribante J (2015) Endotracheal tube cuff pressures in adult patients undergoing general anaesthesia in two Johannesburg academic hospitals. South Afric J Anaesth and Analges 21(3): 81-84.

14. Sengupta P, Sessler DI, Maglinger P, Wells S, Vogt A, et al. (2004) Endotracheal tube cuff pressure in three hospitals, and the volume required to produce an appropriate cuff pressure. BMC Anesthesiology 4(1): 8. 